\title{
Traitement des eaux usées par culture de micro-algues : influence de la composition du milieu sur la croissance de Scenedesmus sp
}

\author{
J.de la Noüel \\ R. van Coillie 2 \\ L. Brunell \\ Y. Pouliot ${ }^{3}$
}

Mots clés : Eaux usées, biotraitement, micro-algues, milieu de croissance, vitamines.

Après une brève revue des projets de traitement d'effluents polluants par culture de micro-algues, les résultats d'un travail de laboratoire, réalisé avec un effluent urbain, sont présentés. Le pouvoir épurateur et la croissance des cultures de Scenedesmus sur milieux modifiés ont été comparés dans le but de connaître les facteurs contrôlables pouvant en influencer la performance. Un épuisement supérieur à $90 \%$ est obtenu en $48 \mathrm{~h}$ pour l'azote et le phosphore. A partir d'un inoculum de faible importante $(2 \mathrm{mg} / \mathrm{L}$ ), l'accroissement de biomasse se poursuit jusqu'au $7 \mathrm{e}$ jour alor 5 que celle-ci atteint environ $350 \mathrm{mg}$ (matière sèche) $/ \mathrm{L}$, sans différence notable entre les trois milieux de culture (effluent brut, effluent filtré et effluent filtré enrichi de $\mathrm{CO}_{2}$ ). L'ajout de vitamines à l'effluent brut ou à un effluent synthétique est sans effet significatif sur la croissance de Scenedesmus sp. Parmi les neuf milieux étudiés, il ressort que l'effluent brut assure une croissance supérieure au milieu synthétique et comparable à l'effluent filtré, même enrichi en $\mathrm{CO}_{2}$. Les résultats obtenus font ressortir le potentiel de Scenedesmus comme agent de traitement tertiaire.

Wastewater treatment by microalgal cultures : influence of the composition of the medium on the growth of Scenedesmus sp.

Keywords: Wastewaters, biotreatment, microalgae, culture medium, vitamins.

After a short review of the present knowledge concerning the treatment of polluting effluents with microalgal cultures, the results of a laboratory work done with a domestic effluent are presented. The epuration capacity and growth of cultures of Scenedesmus made with modified media have been compared in order to identify the controlable factors that may effect performance. For nitrogen and phosphorus a removal of more than $90 \%$ has been obtained within $48 \mathrm{~h}$. Starting with a small inoculum $(2 \mathrm{mg} / \mathrm{L})$ the biomass increased up to the 7 th when it reached about $350 \mathrm{mg}$ dry weight/L, without any noticeable difference between the three culture media used (raw effluent, filtered ef fluent and filtered $\mathrm{CO}_{2}-$ enriched effluent). The addition of vitamins to the raw effluent or to an artificial effluent was without significant effect on Scenedesmus sp. growth. Among the nine media studied, the raw effluent produced a growth superior to that of synthetic medium and similar to that of filtered effluent, even when enriched with $\mathrm{CO}_{2}$. The results obtained demonstrate the potential fo Scenedesmus $\mathrm{sp}$. as a tertiary treatment agent.

\section{Introduction}

L'algue Scenedesmus est largement utilisée depuis une vingtaine d'années dans les systèmes expérimentaux de traitement et valorisation des eaux usèes

\footnotetext{
1. Groupe de recherche en recyclage biologique et aquiculture (GREREBA) Département de Sciences et technologie des aliments, Université Laval, Ste-Foy (Québec), Canada GIK 7P4.

2. Environnement Canada, SCPE, 1179 Bleury, Montréal, Canada, Н3В 3 Н9.

3. Bionov CNP., 81 St-Pierre, suite 480 , Québer 4 A3.
}

d'origine domestique ou agricole (Tableau I). Le principal facteur ayant freiné les applications réside dans la difficulté de récupérer la biomasse. Quoique de nombreux travaux aient exploré différentes méthodes de récolte (cf. Richmond \& Becker 1986), aucun système n'a encore donné de résultat satisfaisant sur le plan de l'efficacité et du coût d'opération. Certaines souches d'algues filamenteuses ont été étudiées et permettent de résoudre le problème de récolte (Buelna et al., 1987), mais ces algues n'atteignent pas les rendements de Scenedesmus sur 
milieu riche en matière organique et en ammoniaque comme, par exemple, les eaux usées brutes ou le lisier de porc (Pouliot et al. 1986). En dépit de cet inconvénient majeur, pour lequel certains travaux lajssent présager des solutions éventuelles (Lavoie \& de la Noüe 1983, Proulx \& de la Noüe 1985 , Buelna et al. 1989), cette algue, par les qualités qu'elle rassemble (Tableau II), prèsente un intérêt certain pour la culture en masse.

L'algue Scenedesmus peut être cultivée sur divers milieux (cf. Tableau I) qui présentent chacun une incidence importante sur les conditions d'exploitation du systeme. Dans le but de connaître les facteurs potentiellement contrôlables pouvant influencer la performance des cultures de Scenedesmus sur eaux usées, nous avons comparé le pouvoir épurateur et la croissance de celles-ci sur des milieux (eaux usées) modifiés. Les facteurs étudiés furent la présence de matières particulaires en suspension dans le milieu et l'abondance du carbone dissous. A cet

Tableau I. Liste des principaux projets de biotechnologies solaires appliquees au traitement des effluents dans le monde (liste non exhaustive, adaptée de Goldman 1979).

\begin{tabular}{|c|c|c|c|c|c|}
\hline Anné & Liev & $\begin{array}{c}\text { Surface des } \\
\text { instailations } \\
\left(\mathrm{m}^{2}\right)\end{array}$ & Especes & Milieu & Sources \\
\hline 1961 & $\begin{array}{l}\text { Etats-Unis } \\
\text { Fehmond celm. }\end{array}$ & 2700 & $\begin{array}{l}\text { Mólange } \\
\text { (Chilorophycses) }\end{array}$ & Eau uste & Oswald. 1969 \\
\hline $\begin{array}{c}1970- \\
71\end{array}$ & Israel & 300 & Chiorelia & Eau usber & $\begin{array}{l}\text { Shelet \& ad. } \\
1976\end{array}$ \\
\hline 1974 & $\begin{array}{l}\text { Etats-Unis } \\
\text { Forl-Plece, fla }\end{array}$ & 8 & Diatomérs & $\begin{array}{l}\text { Eau usêe } \\
\text { eau de mer }\end{array}$ & $\begin{array}{l}\text { Goldman } 1 \\
\text { Ayther. } 1975\end{array}$ \\
\hline $\begin{array}{c}1975- \\
76\end{array}$ & $\begin{array}{l}\text { Etals-Unis } \\
\text { wodts Hole, Mass }\end{array}$ & 1080 & Diatomóes & $\begin{array}{l}\text { Eau usée. } \\
\text { eau de mer }\end{array}$ & $\begin{array}{l}\text { D'Elia \& al. } \\
1977\end{array}$ \\
\hline $\begin{array}{c}1965 \\
79\end{array}$ & $\begin{array}{l}\text { Israei } \\
\text { Mefe }\end{array}$ & 270 & $\begin{array}{l}\text { Melango } \\
\text { (Chlorophyces) }\end{array}$ & Eau usee & $\begin{array}{l}\text { Shelel \& al. } \\
1980\end{array}$ \\
\hline $\begin{array}{c}1976- \\
82\end{array}$ & Singapoure & 2900 & $\begin{array}{l}\text { Mélange } \\
\text { (Micractinium) }\end{array}$ & $\begin{array}{l}\text { Lisier de } \\
\text { porc }\end{array}$ & Goh, 1988 \\
\hline 1977 & $\begin{array}{l}\text { Israel } \\
\text { Yayr }\end{array}$ & 2000 & $\begin{array}{l}\text { Mélange } \\
\text { (Chlorophycees) }\end{array}$ & Eau usáe & $\begin{array}{l}\text { Shelef } 8 \text { al. } \\
\$ 977\end{array}$ \\
\hline 1977 & $\begin{array}{l}\text { États-Unis } \\
\text { Prohmond, Cal }\end{array}$ & 27000 & Micractinium & Eau usoe & $\begin{array}{l}\text { Benemann } 8 \\
\text { al., } 1980\end{array}$ \\
\hline 1978 & Inde & 150 & $\begin{array}{l}\text { Scenodesmus } \\
\text { Spiruling }\end{array}$ & $\begin{array}{l}\text { Dechers } \\
\text { liquides }\end{array}$ & $\begin{array}{l}\text { Venkataraman, } \\
\text { \& } 8 ., 1980\end{array}$ \\
\hline 1978 & $\begin{array}{l}\text { Elars-Unis } \\
\text { Genetrile, Fla }\end{array}$ & 1000 & Scenodesmus & $\begin{array}{l}\text { luswer de } \\
\text { porc }\end{array}$ & $\begin{array}{l}\text { Lincoin \& Hill, } \\
1980\end{array}$ \\
\hline 1982 & $\begin{array}{l}\text { Canada } \\
\text { Valcanes, Oue }\end{array}$ & 100 & Scenedesmus & Eau usde & $\begin{array}{l}\text { de ta Noūe } 8 \\
\text { Al. } 1983\end{array}$ \\
\hline 1984 & Irlande & 30 & Chiorelia & $\begin{array}{l}\text { Lisiet de } \\
\text { porc }\end{array}$ & $\begin{array}{l}\text { Fallowtield } \\
\text { \& Barret, } 1995\end{array}$ \\
\hline 1984 & $\begin{array}{l}\text { Canada } \\
\text { Montmorancy. Oue }\end{array}$ & 39 & Scenedesmus & Eau usłé & $\begin{array}{l}\text { Pouliot \& de } \\
\text { le Noūe, 1985 }\end{array}$ \\
\hline $\begin{array}{c}1885 \\
86\end{array}$ & $\begin{array}{l}\text { Canada } \\
\text { SH-Etienne. Ous. }\end{array}$ & 20 & Hormidtum & Eau usée & $\begin{array}{l}\text { Serodes \& al. } \\
1986\end{array}$ \\
\hline 1987. & $\begin{array}{l}\text { Etats-Unis } \\
\text { Hater, ce }\end{array}$ & 60000 & Mélange & Eau usen & Oswald, $198 B$ \\
\hline
\end{tabular}

Tableau II. Avantages et inconvénients de l'algue Scenedesmus pour le traitement et la valorisation des eaux usées.

\begin{tabular}{|c|c|}
\hline Aventages & Inconvenients \\
\hline 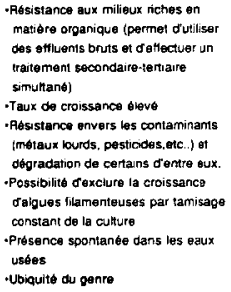 & $\begin{array}{l}\text {-Récolte difficle (coúteuse) } \\
\text { +faibie digestibilite de la buomasse } \\
\text { (présence d'une paroi cellulosique) } \\
\text {-Faible valeur marchence de la } \\
\text { biomasse }\end{array}$ \\
\hline
\end{tabular}

effet, nous avons mené des expériences sur l'effet d'une filtration du milieu brut et sur l'enrichissement des cultures en $\mathrm{CO}_{2}$.

Les eaux usées constituent un milieu de prédilection pour la croissance de micro-algues. Aubert \& Daniel (1968) ont observé une croissance phytoplanctonique sur eaux d'égoûts supérieure à celle obtenue avec les meilleurs milieux artificiels. Une hypothèse proposée est la production de facteurs de croissance par les bactéries des eaux d'égoûts. Dans le but de vérifier l'effet possible des métabolites bactériens, nous avons donc réalisé des cultures sur effluent brut, filtré autoclavé, et ultrafiltré. Le traitement à l'autoclave élimine de l'effluent certaines vitamines et les bactéries productrices. L'ultrafiltration élimine également les bactéries ainsi que les facteurs éventuels de croissance de poids moléculaire supérieur à 50000 .

Bougis (1974) rapporte que $70 \%$ du phytoplancton marin requierent de la vitamine $B_{12}$. Il conclut aussi que la thiamine est liée à la production primaire phytoplanctonique, sans qu'on sache exactement comment. Par contre il n'observe pas d'amélioration de la croissance avec la biotine. L'idée généralement admise est que les algues vertes d'eau douce sont insensibles aux vitamines (cf les travaux d'Aubert 1963, sur Scenedesmus, Chlamydomonas ou Chlorella). Jorgensen (1979) donne, après revue bibliographique, un tableau des besoins en vitamines (biotine, thiamine, $B_{12}$ ) des différentes familles d'algues. Pour les Chlorophycées, un petit nombre 
nécessite de la thiamine $\left(B_{1}\right)$ et un grand nombre de la cyanocobalamine $\left(B_{12}\right)$, la biotine, elle, n'étant jamais indispensable. Dans le but d'évaluer l'importance des vitamines pour la croissance de Scenedesmus, nous avons enrichi un milieu artificiel en thiamine, biotine et $B_{12}$.

\section{Matériel et méthodes}

\subsection{Milieux de culture}

L'effluent est celui de la station d'épuration de la base militaire de Valcartier, située aux environs de Québec. Les eaux usées sont des rejets classiques de type urbain ayant subi une décantation (traitement primaire) et un traitement secondaire par boues activées. L'effluent est alors rejeté en rivière. La teneur moyenne en phosphore de l'effluent secondaire est de 20 à $75_{\mu} \mathrm{M}$ P-PO ${ }_{4}^{-3}$, et la teneur moyenne en azote $\left(\mathrm{N}-\mathrm{NH}_{4}{ }^{+}\right)$de 600 à $900{ }_{\mu} \mathrm{M}$. Les teneurs en nitrate et nitrite sont négligeables (de la Noüe et al 1980). Le pH observé est neutre et stable, autour de 7,3. Au laboratoire, l'effluent est conservé à l'obscurité, à $4^{\circ} \mathrm{C}$. La filtration des effluents est effectuée, le cas échéant, avec des filtres Whatman 94-AH. Le milieu artificiel utilisé est le milieu de base pour les micro-algues d'eau douce (Nichols 1973).

\subsection{Mode de culture}

Les cultures, menées en duplicata ou en triplicata, sont réalisées au laboratoire, en vrac (« batch»), dans des erlenmeyers de 1 ou 6 litres dans des chambres de cultures thermostatées à $22 \pm 1^{\circ} \mathrm{C}$. La lumière est fournie par des tubes fluorescents (intensité incidente de $150{ }_{\mu} \mathrm{E} \cdot \mathrm{m}^{-2} \cdot \mathrm{s}^{-1}$ ) selon un rythme nycthéméral $12 / 12$ qui reproduit les conditions climatiques estivales moyennes. Le bullage des cultures est assuré par l'injection d'air atmospherique, à l'exception des cultures enrichies en $\mathrm{CO}_{2}$ pour lesquelles un mélange ( $5 \%$ de $\mathrm{CO}_{2}$ ) sous pression est fourni.

\subsection{Méthodes d'analyse}

Les nutriments $\left(\mathrm{N}-\mathrm{NH}_{4}+\right.$ et $\mathrm{P}_{-} \mathrm{PO}_{4}{ }^{-3}$ ) sont dosës à l'aide d'un autoanalyseur II Technicon selon les méthodes décrites par Strickland \& Parsons (1972). Les numérations cellulaires sont réalisées à l'aide d'un hémocytomètre Malassez (précision $\pm 5 \%$, pour des dénombrements d'environ 1000 cellules). La biomasse sèche est estimée par pesée sur une balance Mettler H51AR, après séchage durant $24 \mathrm{~h}$ à $95^{\circ} \mathrm{C}$ d'une aliquote filtrée sur Whatman GFC (précision $\pm 5 \mathrm{mg} \cdot \mathrm{L}^{-1}$ ). Selon plusieurs auteurs (Sorokin 1973, Cloern 1976) la densité optique à $678 \mathrm{~nm}$ représente une variable d'état, caractérisant la biomasse des algues. Nous avons donc mesuré la densité de nos cultures à l'aide d'un spectrophotomètre Bausch et Lomb-Spectronic 600 (cuves de $1 \mathrm{~cm})$.

\section{Résultats et discussion}

\subsection{Epuration du milieu sur divers effluents}

Les données relatives à l'épuisement des nutriments sont présentées aux figures 1 et 2 . Après $24 \mathrm{~h}$, l'enlèvement est d'environ $30 \%$ pour l'azote et $50 \%$ pour le phosphore. Une épuration pratiquement complète $(\geqslant 90 \%)$ de l'azote et du phosphore est obtenue après 48 heures. Le système considéré joue donc parfaitement son rôle d'épuration de la charge minérale en excès dans l'effluent.

Les vitesses d'élimination de $\mathrm{N}-\mathrm{NH}_{4}+$ et $\mathrm{P}_{-} \mathrm{PO}_{4}{ }^{-3}$, estimées à partir des quantités de nutriment consommé pendant les 15 premières heures, sont

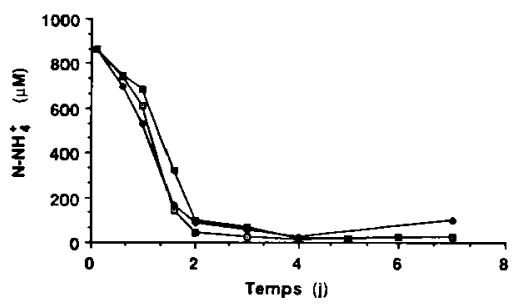

Fig. I. Enlèvement de l'azote ammoniacal dans les cultures de Scenedesmus sp. sur effluents brut $(\boldsymbol{a})$, filtré $(\bullet)$ et filtré $\&$ enrichi en $\mathrm{CO}_{2}(\bullet)$.

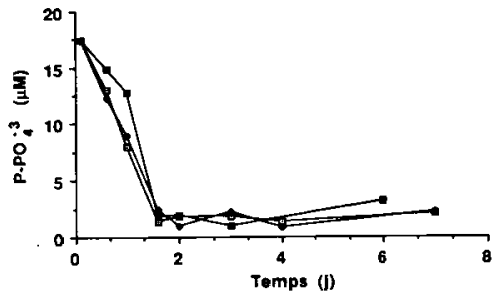

Fig. 2. Enlèvement du phosphore inorganique dans les cultures de Scenedesmus sp. sur effluents brut ( $(\theta)$, filtré $(\bullet)$ et filtré et enrichi en $\mathrm{CO}_{2}(\bullet)$. 
Tableau III. Vitesses d'enlèvement de l'azote ammoniacal $\left(V_{V}\right)$ et de l'orthophosphate $\left(V_{P}\right)$ pour les différents types d'effluents.

\begin{tabular}{|c|c|c|}
\hline Milieu de cutture & $\begin{array}{c}V_{N} \\
\left(\mu g \text {-at } N 10^{3} \text { cell. } h^{-1}\right)\end{array}$ & $\begin{array}{c}V_{p} \\
{[\mu g \text {-at P.10-8 }}\end{array}$ \\
\hline \multirow[t]{2}{*}{ Ettluent onst } & 209 & 6 \\
\hline & 131 & $B$ \\
\hline \multirow{2}{*}{ Etfluent filtre } & 254 & * \\
\hline & 196 & 8 \\
\hline \multirow[t]{2}{*}{ Ettluent filtré $+\mathrm{CO}_{2}$} & 203 & $\mathbf{s}$ \\
\hline & 148 & 3 \\
\hline
\end{tabular}

présentées au tableau III. Ces résultats rendent compte des vitesses moyennes et non maximales ; en effet, les 15 premières heures incluent la phase obscure, où la consommation d'azote est réduite. En outre, on n'obtient la vitesse maximale de consommation qu'avec des algues initialement en état de jeûne.

Des travaux antérieurs (Dauta et al 1982) ont permis de calculer pour Scenedesmus crassus les vitesses maximales de consommation pour l'azote $\left(\mathrm{V}_{\mathrm{N}}\right.$ $=310 \mu$ g.at $\mathrm{N}^{-N_{3}} \cdot 10^{-9}$ cell. $\mathrm{h}^{-1}$ ) et le phosphore $\left(\mathrm{V}_{\mathrm{P}}=62 \mu \mathrm{g}\right.$. at $\mathrm{P}-\mathrm{PO}_{4}^{-3} \cdot 10^{-9}$ cell. $\left.\mathrm{h}^{-1}\right)$. Jorgensen (1979) rapporte, pour les Chlorophytes, une vitesse de prise en charge de $4000 \mu$ g-at $\mathrm{N}_{-} \mathrm{NO}_{3}^{-} \cdot 10^{-9}$ cell. $h^{-1}$, ce qui semble énorme. Il mentionne également une vitesse de $12 \mu \mathrm{g}$-at $\mathrm{P}_{-} \mathrm{PO}_{4}{ }^{-3} 10^{-9}$ cell.h-1 pour le genre Scenedesmus, résultat comparable au nôtre. Dans l'ensemble, les résultats indiquent qu'il n'y a pas de différence notable, dans le rendement épuratoire du système, entre les différents milieux.

\subsection{Croissance sur différents effluents}

Afin d'obtenir plus de fiabilité dans l'interprétation des résultats, trois types de mesures ont été effectuées : biomasse en suspension, densité optique et numération cellulaire. Les résultats relatifs à la densité optique sont présentés à la figure 3 . Les courbes de croissance obtenues sont typiques des cultures de micro-organismes : période de latence, phase exponentielle, puis inflexion des courbes après 4 ou 5 jours. La biomasse continue alors à augmenter jusqu'au $7^{\mathrm{e}}$ jour. La biomasse d'algues obtenue est alors de 300 à $400 \mathrm{mg}-\mathrm{L}^{-1}$ (matière sèche) à partir d'une biomasse initiale faible, de l'ordre de $2 \mathrm{mg} . \mathrm{L}^{-1}$, pratiquement indissociable de la biomasse résiduelle de l'effluent décanté (évaluée à 5-6 mg. $\mathrm{L}^{-1}$ ).

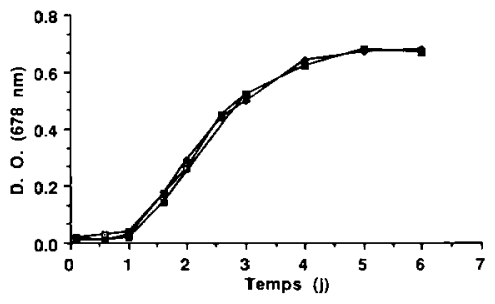

Fig. 3. Evolution de la densité optique dans les cultures de Scenedesmus $\mathrm{sp}$. sur effluents brut ( $(\square)$, filtré $(\diamond)$ et filtré et enrichi en $\mathrm{CO}_{2}(\bullet)$.

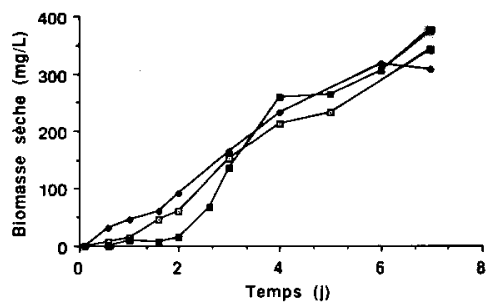

Fig. 4. Evolution de la biomasse (matière sèche) dans les cultures de Scenedesmus sp. sur effluents brut ( $\boxminus$ ), filtré (૯) et filtré et enrichi en $\mathrm{CO}_{2}(\bullet)$.

Tarifeno-Silva et al (1982) et Kawasaki et al (1982) ont obtenu, sur effluent brut, une biomasse de Scenedesmus de $180 \mathrm{mg} . \mathrm{L}^{-1}$ après 2 jours, mais avec une biomasse initiale de $70-100 \mathrm{mg} . \mathrm{L}^{-1}$. Aucune différence marquée n'est décelable entre les cultures sur effluent brut, effluent filtré et effluent filtré et enrichi en $\mathrm{CO}_{2}$ (fig. 3 et 4).

La figure 5 présente les résultats de la même expérience en termes de populations cellulaires dans les cultures. Bien que la position relative des courbes soit la même que celles obtenues selon la densité optique et la biomasse, on remarque une diminution du nombre de cellules en fin de culture. Cette apparente contradiction (la biomasse augmente alors que la population cellulaire est stable ou diminue) indique en réalité que la croissance s'effectue probablement plus par agrandissement des cellules (jours 4 à 7) que par leur 


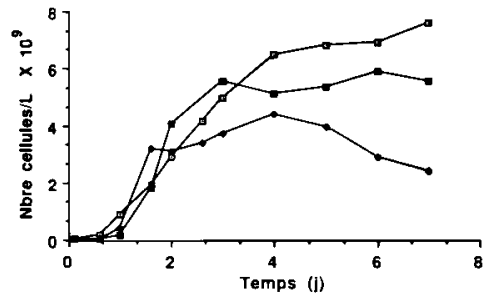

Fig. 5. Evolution de la population cellulaire dans les cultures de Scenedesmus sp. sur effluents brut (a), filtré (†) et filtré et enrichi en $\mathrm{CO}_{2}(\boldsymbol{0})$.

division (jours 1 à 3). Les taux de croissance calculés pendant la phase exponentielle ne devraient donc pas être très différents.

Les estimations de densité optique sont moins entachées d'erreur que celles de biomasse, en particulier pour les faibles concentrations d'algues. De plus, on dispose facilement de données plus nombreuses. C'est donc à partir de ces résultats que nous pourrons évaluer de la manière la plus fiable le taux de croissance des cultures. La croissance d'une population " $\mathbf{A}$ " se définit dans le temps par l'expression $\mathrm{dA} / \mathrm{dt}=\mu \mathrm{A}$, où " $\mathrm{t}$ » est le temps en jour et $" \mu$ " est le taux de croissance de la population $\left(\mathrm{j}^{-1}\right)$. L'expression " $\mu$ " peut s'écrire sous la forme d'un taux de croissance maximal " $\mu_{\max }$ ", spécifique de la population, affecté de facteurs de réduction traduisant des conditions non optimales en lumière, température et nutriments (azote et phosphore). La connaissance de « $\mu$ », bien qu'essentielle à la compréhension et à la précision de la croissance d'une population est extrêmement délicate. Différents mécanismes interviennent : assimilation, variation des stocks internes, taille de la population, etc... avec de nombreux contrôles en retour d'un facteur sur un autre. Afin d'obtenir une valeur la plus représentative possible de la croissance de chacune des cultures, nous avons calculé le taux moyen de crois-

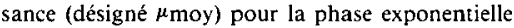
(arbitrairement assignée à la période comprise entre le jour 1 et le jour 4).

Les taux de croissance calculés (Tableau IV) pour l'effluent brut se situent donc autour de $1,00 \mathrm{j}^{-1}$, soit
Tableau IV. Taux de croissance ( ${ }_{\mu}$ moy) de Scenedesmus sp sur différents types d'effluents.

\begin{tabular}{|c|c|c|}
\hline $\begin{array}{l}\text { Mineu de } \\
\text { cuhure }\end{array}$ & $\begin{array}{c}\text { Taux do } \\
\text { croissance } \\
(j-1)\end{array}$ & $\begin{array}{l}\text { Nomber do } \\
\text { divisions } \\
\text { par jour }\end{array}$ \\
\hline \multirow[t]{3}{*}{ Effluent brut } & 0,99 & 1.43 \\
\hline & 0.92 & 1.33 \\
\hline & 1.09 & 1,58 \\
\hline \multirow[t]{2}{*}{ Etfluent filtre } & 0.94 & 1,38 \\
\hline & 1.07 & 1,55 \\
\hline \multirow[t]{2}{*}{ Etfluent fitse $+\mathrm{CO}_{2}$} & 1.08 & 1,57 \\
\hline & 1,13 & 1,64 \\
\hline
\end{tabular}

environ 1,45 division par jour $(\mu / \ln 2)$. En dépit d'une stimulation attendue de la croissance par le $\mathrm{CO}_{2}$ (de la Noüe et al 1984), on remarque que le taux de croissance en présence de $\mathrm{CO}_{2}\left(1,11 \mathrm{j}^{-1}\right)$ n'est guère supérieur à celui mesuré pour les algues cultivées sur effluent brut ou filt ré (Tableau IV). Dans des travaux antérieurs (Brunel \& Guerri 1980) avec Scenedesmus crassus, un taux de croissance maximal de $1,62 \mathrm{j}^{-1}$ a été obtenu alors que Mur et al (1978) donnent pour le genre Scenedesmus 1,58 $\mathrm{j}^{-1}$. Ces valeurs sont inférieures à celle $\left(2,08 \mathrm{j}^{-1}\right)$ que donnent Lehman et al (1975) pour les algues vertes. Jorgensen (1979) relève pour le phytoplancton des taux de 1,3 à $2,5 \mathrm{j}^{-1}$ dans la littérature. Les croissances obtenues dans nos conditions sont donc comparables à celles de la littérature.

\subsection{Influence des vitamines}

Avec les effluents autoclavés et ultrafiltrés, les résultats, non présentés ici, montrent que ces traitements n'influencent pas grandement la croissance de Scenedesmus. Il n'y a pas non plus de différence évidente avec les cultures sur effluent brut ou filtré. Nous avons donc, dernière étape de l'expérience, réalisé des cultures sur effluents brut et synthétique enrichi en vitamines.

L'examen des résultats (Tableau $\mathrm{V}$ ), exprimés en ${ }_{\mu}$ moy, montre que l'ajout de vitamines n'a pas d'action significative sur la croissance de Scenedesmus. De plus, toutes les valeurs obtenues sur milieux vitaminés sont inférieures à celles obtenues sur effluent brut, ces dernières se situant même parmi les valeurs

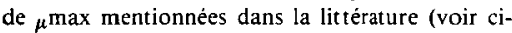
dessus). 
Tableau V. Taux de croissance ( $\mu$ moy) de Scenedesmus sp sur milieu artificiel enrichi ou non en vitamines et sur effluent brut.

\begin{tabular}{|c|c|c|}
\hline $\begin{array}{l}\text { Milieu de } \\
\text { culture }\end{array}$ & $\begin{array}{c}\text { Taux de } \\
\text { croissance } \\
\left.\text { (j" }{ }^{*}\right)\end{array}$ & $\begin{array}{l}\text { Nombre do } \\
\text { divisions } \\
\text { par jour }\end{array}$ \\
\hline \multirow[t]{2}{*}{ Antifictol } & 1,04 & 1.51 \\
\hline & 1.21 & 1,75 \\
\hline \multirow{2}{*}{ - Thiamine } & 0.97 & 1,41 \\
\hline & 1.33 & 1.93 \\
\hline \multirow[t]{2}{*}{$\cdot+$ Biotine } & 1,04 & 1,51 \\
\hline & $\mathrm{T} .18$ & 1,71 \\
\hline \multirow[t]{2}{*}{$\because+B_{12}$} & 1.10 & 1,59 \\
\hline & 1.23 & 1,78 \\
\hline \multirow[t]{2}{*}{ Emluent ont } & 1,65 & 2,39 \\
\hline & 1,66 & 2.49 \\
\hline
\end{tabular}

\section{Conclusion}

Aucune des conditions étudiées, à l'exception de l'enrichissement en $\mathrm{CO}_{2}$, ne semble justifiée, puisque c'est l'effluent brut qui assure la meilleure croissance de Scenedesmus. Par ailleurs, la présence ou non de vitamines dans un milieu artificiel ne semble pas influencer la croissance de cette dernière. Comme le souligne Kuentzel (1970), le carbone d'origine bactérienne pourrait expliquer la bonne croissance observée sur effluent brut. Plus précisément, on peut proposer une stimulation spécifique de la part des bactéries sur la croissance de la microalgue. Dakhama et al (1988) ont en effet démontré l'existence d'interactions inhibitrices ou stimulatrices de certains taxons bactériens sur la croissance de Chlorophycées et de cyanobactéries.

Le système de culture de Scenedesmus sur eaux usées présente un potentiel élevé à la fois pour le traitement tertiaire (et secondaire) des eaux usées et pour la production de biomasse. Des travaux visant à améliorer les moyens de récolte sont encore nécessaires avant de permettre la mise en application de ce système sur une plus vaste échelle.

\section{Remerciements}

Ce travaił a été rendu possible grâce au support financier du Conseil des recherches en sciences naturelles et gènie du Canada (thematique-biotechnologie), du Fonds FCAR du Québec et de la Compagnie Eco-Recherches, Montréal.

\section{Travaux cités}

Aubert (M.). 1963. - Possibilité d'adaptation diététique de la biomasse planctonique. Cahiers du Cerbom, 2 : 24-34.

Aubert (M.) \& Daniel (S.). 1968. - Eaux résiduaires et plancton. Rev. Intern. Océanogr. Med., $10: 93-110$.

Benemann (J.R.), Koopman (B.), Weissman (J.), Eisenberg (D.) \& Geopel (R.). 1980. - Development of microalgae harvesting and high-rate pond technologies in California. $\mathbf{I n}: \mathbf{G}$. Shelelf, G. \& Soeder, C. J. (eds), Algae Biomass, Elsevier/Holland Biomedical Press, Amsterdam : 457-495.

Bougis (P.). 1974. - Ecologie du plancton marin. 1. Le phytoplancion, Masson, Paris, 196 p.

Brunel (L.) \& Guerri (M.M.). 1980. - Cinétique d'assimilation et de croissance de Scenedesmus crassus, érude expérimentate el modélisation. Thèse de $3^{e}$ cycle, Université PaulSabatier, Toulouse, $226 \mathrm{p}$.

Buelna (G.), Pouliot (Y.) \& de la Noüe (J.). 1987. - Performance and operating parameters of a photobioreactor. In : Stadler T., Mollion J., Verdus M.C., Karamanos Y., Morvan H \& Christiaen D. (eds), Algal Biotechnology, Elsevier Applied Science Publ, Barking, England : 189-198.

Buelna (G.), Bhattarai (K.K.), de la Noüe (J.) \& Taiganides (E.P.). 1989. - Evaluation of various floculants for the recovery of algal biomass grown on pigwaste. Biol, Wastes 31 : 211-222.

Cloern (J.E.). 1976. - Population dynamics of Cryptomonas ovata. A laboratory field and computer simulation study. These Ph. D., Washington State University, Department of Zoology. 102 p.

Dakhama (A.), de la Noüe (J.) \& Lavoie (M.). 1988. - Effets stimulateurs et inhibiteurs de Pseudomonas sur la croissance de micro-algues. Comptes-rendus, $15^{\text {e }}$ Colloque annuel sur la toxicologie aquatique, Montréal, 28-30 novembre : 45-50.

Dauta (A.), Brunel (L.) \& Guerri (M.M.). 1982. - Determination expérimentale des paramètres liés à l'assimilation de l'azote et du phosphore par Scenedesmus crassus. Annls Limnol., 18 (1) : 33-40.

D'Elia (C.F.), Ryther (J.H.) \& Losordo (T.M.). 1977. - Productivity and nitrogen balance in large scale phytoplankton culture. Water Res., 11: 1031 -1040.

de la Noüe (J.), Picard (G.), Piette (J.P.) \& Kirouac (C.). 1980. - Utilisation de l'algue Oocyris sp. pour le traitement tertiaire des eaux usées. Il. Effet de conditionnement préalable des cellules en cyciostat sur leur vitesse de prise en charge de l'azote lors d'incubation de longue durée. Wat. Res. 14 : 1125-1130.

de la Noüe (J.), Thellen (C.) \& Van Coillie (R.). 1983. - Traitements tertiaires d'eaux usees municipales par production de biomasses d'algues. Rapport de recherche présenté à Agriculture Canada, Eco-Recherches Ltée et Centre de recherche en nutrition, $155 \mathrm{p}$.

de la Noüe (J.), Cloutier-Mantha (L.), Walsh (P.) \& Picard (G.). 1984. - Influence of Agitation and Aeration Modes on Biomass Production by Oocystis sp. Grown on Wastewaters. Biomass $4: 43-58$.

Fallowfield (H.D.) \& Barret (M.K.). 1985. - The photosynthetic treatment of pig slurry in temperate climatic conditions : a pilot plan study. Agricult. Wastes, 12:111-136.

Goh (A.). 1986. - Production of microalgae using pig waste as a substrate. In Barclay W.R. \& Mclntosh, R.P. (éds), Algal Biomass Technologies J. Cramer, Berlin : 235-244. 
Goldman (J.). 1979. - Outdoor algal mass cultures. I. Applications. Wat. Res., $13: 1-19$.

Goldman (J.C.) \& Ryther (J.H.). 1975. — Nutrient transformations in mass cultures of marine algae. J. Environ. Eng. Div. Am. Soc. Civ. Engin., 101, EE3 : 351-364.

Jorgensen (S.E.). 1979. - Handbook of environmental data and ecological parameters. Jorgensen (éd.). Int. Soc. Ecol. Modell., 1162 p.

Kawasaki (L.Y.), Tarifeño-Silva (E.), Yu (D.P.), Gordon (M.S.) \& Chapman (D.J.). 1982. - Aquacultural approaches to recycling of dissolved nutrients in secondarily treated domestic wastewaters. I. Nutrient uptake and release by artificial food chains. Wat. Res., $16: 37-49$.

Kuentzel (L.E.). 1970. - Bacteria-algae symbiosis : a cause of algal bloom. In Bioresources of shallow water environments. Proceedings of the Symposium of Hydrobiology. Ed. WeistGreeson - the American Water Resources Association.

Lavoie (A.) \& de la Noüe (J.). 1983. - Harvesting microalgae with chitosan and economical feasibility. J. World Mariculture Soc., $14: 685-694$.

Lehman (J.T.), Botkin (D.B.) \& Likens (G.E.). 1975. - The assumptions and rationales of a computer model of phytoplancton population dynamics. Limnol. Oceanogr. 20 : 343-364

Lincoln (E.P.) \& Hill (D.T.). 1980. - An integrated microalgae system. In Shelef, G. \& Soeder, C.J. (éds), Algae Biamass, Elsevier/North-Holland Biomedical Press, Amsterdam : 229-244.

Mur (L.R.), Gons (H.J.) \& Vanlière (L.) 1978, - Competition of the green alga Scenedesmus and the blue green alga Oscillatoria. Mitt. Int. Verh. Limnol., $21:$ 473-479.

Nichols (H.W.). 1973. - Growth media : freshwater. In J.R. Stein (ed), Handbook of phycological methods, Cambridge : $7-24$.

Oswald (W.J.). 1969. - Current status of microalgae from wastes. Chem. Eng. Prog. Symp. Ser., 65: 87-92.

Oswald (W.J.). 1988. - Micro-algae and waste-water treatment. In Borowitzka, M.A. \& Borowitzka L.J. (éds), Micro-algal biotechnology, Cambridge University Press, Cambridge : 305-328.

Pouliot (Y.) \& de la Noüe (J.). 1985. - Mise au point d'une installation pilote de traitement tertiaire des eaux usées par microalgues. Rev. Frcse Sci. Eau, $4: 207-222$.

Pouliot (Y.), Buelna (G.) \& de la Noüe (J.). 1986. - Caractérisation de différentes micro-algues pour la valorisation d'effluents polluants. Proceedings of the Renewable Energy Conference' 86. «Solar Energy Society of Canada Inc ». and "The Biomass Energy Institute Inc $n$, Winnipeg, 23-26 June : 5-9.
Proulx (D.) \& de la Noüe (J.). 1985. - Growth of Daphnia magno on urban wastewater tertiarily treated with Scenedesmus sp. Aquacult. Engineer., 4 : 93-111.

Richmond (A.) \& Becker (W.). 1986. - Technological aspecrs of mass cultivation - a general outline, in Richmond A. (éd.), Handbook of microalgal mass cuhure, CRC Press Inc., Boca Raton, Florida : 245-263.

Sérodes (J.-B.), Waligora (J.J.) \& de la Noúe (J.). 1986. - Traitement tertiaire des eaux usées domestiques par microalgues. Proceedings, 9 th Symposium on wastewater treatment. Montréal, 11-12 novembre : 237-249.

Shelef (G.), Schwartz (M.) \& Schechter (H.). 1973. - Prediction of photosynthetic biomass production in accelerated algal-bacterial wastewater treatment systems, in Jenkins, S.H. (éd.), Advances in Water Pollution Research, Pergamon Press, Oxford : 181-189.

Shelef (G.), Moraine (R.), Meydan (A.) \& Sandbank (E.). 1976. - Combined algae production-wastewater treatment and reclamation system. In Schlegel, H.G. \& Barnea J. (Eds.), Microbial Energy Conversion, Erich Goltze kg, Göttingen : 427-442.

Shelef (G.), Oron (G.) \& Moraine (R.). 1977. - Combined systems for algal wastewater treatment and reclamation and protein production, Environmental Engineering Research Center, Technion, Haifa.

Shelef (G.), Azov (Y.), Moraine (R.) \& Oron (G.). 1980. - Algal mass production as an integral part of a wastewater treatment and reckamation systems. In : Shelef G. \& Soeder C.J. (eds), Algae Biomass, Elsevier/North-Holland Biomedical Press, Amsterdam : 163-89.

Sorokin (C.) .1973 . - Dry weight, packed cell volume and optical density. In Stein J.R. (éd.), Handbook of phycological methods, Cambridge University Press : 321-343.

Strickland (J.D.H.) \& Parsons (T.R.). 1972, - A practical handbook of sea water analysis. Fisheries research board of Canada (éd), $310 \mathrm{p}$.

Tarafeño-Silva (E.), Kawasaki (L.Y.), Yu (D.P.), Gordon (M.S.) \& Chapman (D.J.). 1982. - Aquacultural approaches to recycling of dissolved nutrients in secondarily treated domestic wastewaters. II. Biological productivity of artificial food chains. Wat. Res., 16:51-57.

Venkataraman (L.V.), Nigam (B.P.)\& Ramanathan (P.K.). 1980. - Rural oriented freshwater cultivation and production of algae in India. In : Shelef G. \& Soeder C.J. (eds), Algae Biomass, Elsevier/North-Holland Biomedical Press, Amsterdam : $81-95$. 